\title{
CONQUERING THE “DREADED” BLACK TRIANGLES: A CASE SERIES
}

Nehal Sanghani1 ${ }^{1}$, Ashwini Apine ${ }^{2}$, Shivaprasad B. M $^{3}$, Ritesh $\mathrm{K}^{4}$, Nalini M. S

\section{HOW TO CITE THIS ARTICLE:}

Nehal Sanghani, Ashwini Apine, Shivaprasad B. M, Ritesh K, Nalini M. S. "Conquering the "Dreaded" Black Triangles: A Case Series". Journal of Evolution of Medical and Dental Sciences 2014; Vol. 3, Issue 17, April 28; Page: 4636-4642, DOI: $10.14260 /$ jemds/2014/2488

ABSTRACT: One of the most difficult and elusive goals of Periodontics in the field of reconstruction and regeneration is the surgical reconstruction of the lost interdental papilla. This clinical and aesthetic dilemma demands more attention from the clinician. Several non-surgical and surgical techniques have been proposed to manage the interproximal space. Non-surgical approaches modify the interproximal space and the surgical techniques aim to re-contour, preserve and reconstruct the soft tissue between the teeth. Platelet rich fibrin has been extensively used in hard and soft tissue augmentation, but not tried for augmenting interdental papilla. The purpose of this case series is to describe a novel approach of papilla reconstruction in the maxillary anterior region with the use of platelet rich fibrin. This procedure obtained optimal fill in all the cases postoperatively. Thus, the use of PRF may be the panacea for interdental papilla augmentation.

KEYWORDS: Interdental Papilla; Platelet Rich Fibrin; Regeneration; Esthetics; Periodontal Plastic Surgery.

INTRODUCTION: In recent years, esthetic demands in dentistry have increased rapidly, driven by an enhanced awareness of beauty and esthetics. The ultimate goal in modern dentistry is to achieve "white" and "pink" esthetics. "White esthetics" are the natural dentition or the restoration of dental hard tissues with suitable materials. "Pink esthetics" refers to the surrounding hard and soft tissues, which can enhance or diminish the esthetic result.

Today, in majority of the adult population with a history of periodontal disease, open gingival embrasures are a common problem. Black triangles occur in more than one third of adults. ${ }^{1,2}$ Black triangles are unesthetic, but they also contribute to retention of food debris, and can adversely affect the health of the periodontium. ${ }^{3}$ One of the major aesthetic challenges in periodontal plastic surgery is related to the ability of rebuilding the lost papilla in the maxillary anterior segment.

A black triangle or an open gingival embrasure occurs as a result of a deficiency or loss of papilla beneath the contact point. The loss of gingival embrasures occurs due to several factors including periodontal disease, length of embrasure area, root angulations, interproximal contact position, changes in papilla during orthodontic alignment and triangular-shaped crowns. ${ }^{1,2}$ Also deficiency of the papillae might be a consequence of post periodontal surgery.

Over the years, a number of non-surgical and surgical techniques were used either to recontour or reconstruct the interdental papilla. Non-surgical techniques consisted of repeated curettage of the interdental papilla. ${ }^{4}$ Surgical techniques essentially comprised of pedicle and free gingival and connective tissue grafts. ${ }^{5-13}$ Some case reports have demonstrated success with subepithelial connective tissue graft ${ }^{11,13}$ and orthodontic therapy. ${ }^{14}$

One of the most challenging and least predictable problems in the field of periodontal plastic surgery is the reconstruction of the lost interproximal papilla. All the surgical procedures mentioned above had unpredictable results owing to the small dimension of the papillary space and the vascular 
supply to this area. Inadequate blood supply and anatomical considerations make papillary reconstruction procedures more challenging for the clinician.

The purpose of this case report is to describe a novel approach of papilla reconstruction with an interdisciplinary approach to enhance esthetics.

CASE SERIES: Four patients with good general and periodontal health ( 2 men, 2 women) with age ranging from 23-45 years, with a chief complaint of unesthetic smile and partial loss of papilla in the anterior region were recruited in this study. Papilla Presence Index (PPI) was used to assess the relationship of the papilla with the CEJ and the adjacent teeth. ${ }^{14}$ All the selected cases presented with a PPI score of 2. Clinical and radiographic evaluation was made for each patient before treatment. Since there was no bone loss radiographically and there was only soft tissue loss, complete reconstruction of the papilla was expected. The surgical procedure was explained to the patient and informed consent was obtained.

SURGICAL METHOD: Adequate local anesthesia was achieved. A split thickness semilunar incision was given about $1 \mathrm{~mm}$ coronal to the mucogingival junction in the interdental region of involved teeth. Through the semilunar incision toward the interdental papillae, the split thickness flap was continued to create a pouch in the interdental area. A curette was used around the necks of involved teeth to free the tissue attachment from the root surface, facilitating the displacement of gingivopapillary unit coronally.

Platelet rich fibrin was obtained from patient's blood as per Choukroun's guidelines. This PRF was squeezed to form a membrane which was eased in to the pouch and pushed coronally, enabling to fill the bulk of the interdental papillae. The incisions were secured using sutures.

The surgical area was protected with a periodontal dressing. Figure 1 through figure 5 shows the surgical procedure in detail. The pre-operative view of rest of the treated cases are shown in figures 6, 7, 8 and the post-operative views in figures 6a, 7a, 8a respectively. Analgesics (Ibuprofen $400 \mathrm{mg}$ twice daily for 3 days) along with chlorhexidine digluconate $(0.12 \%)$ rinse twice daily were prescribed for 10 days. Postoperative healing was uneventful with minimal pain. Review of the patient on 10th day revealed complete fill of the interdental papilla, with the conversion of PPI from 2 to 1 in all of the cases. All the cases were followed-up for 1 month.

DISCUSSION: The black triangles pose a problem to aesthetics and contribute for food retention and they may affect the periodontal health. ${ }^{15}$ A correct diagnosis is essential for either the success or improvement of the treatment of papilla loss, as their etiological factors must be eliminated before considering therapies for reconstruction. In addition to act as a barrier to protect the periodontal structures, the papilla plays a critical role in the aesthetics.

Therefore, it is very important to respect the papillary integrity during the dental procedures and minimize its disappearance. ${ }^{16}$

The etiology of the papillary loss is multifactorial. The causes include changes in papilla during orthodontic alignment, loss of periodontal ligament resulting in recession, loss of alveolar bone height in relation to the interproximal contact, ${ }^{17}$ length of the area of the niche, root angle, and positioning of the interproximal contact and triangle-shaped crowns. ${ }^{15,17}$ 
To date various treatment modalities have been advocated and implemented for the treatment of unpleasant black triangles in aesthetic zone. These treatments can either be nonsurgical or surgical. Repeated curettage to stimulate the regrowth of interdental papillae in necrotizing ulcerative gingivitis was advocated by Shapiro et al. ${ }^{3}$

Surgical treatment options include the use of pedicle graft with coronal displacement of the gingivopapillary unit and subepithelial connective tissue grafting, ${ }^{6}$ interpositional subepithelial connective tissue grafting and use of buccal and palatal split thickness flap. ${ }^{8}$ Interdental papilla augmentation along with reconstruction of interdental bone to create appropriate support for gingival papilla has also been reported. ${ }^{9}$

Limited blood supply is believed to be one of the major reasons why papilla preservation and regeneration are difficult. ${ }^{15}$ The predictable creation of the lost gingival papilla by surgical means must follow the principle of using the most advantageous pattern of blood supply to the newly created tissue. Due to the small, restricted space interdentally, any form of free grafting cannot be utilized since the surface area for blood supply to the donor tissue is minimal.

A specific incision design (papillary sparing) was utilized in the present case series to retain maximum vascularity and minimize scar tissue formation. The atraumatic management of the tissues, respect for the blood supply and avoidance of tension and pressure are critical for the viability of the tissues and the success for the procedure. This flap design used here, maximizes the soft tissue vascularity and the primary wound closure. ${ }^{18}$

The main advantage of using a tunnel or a pouch like design was the dual blood supply from the underlying connective tissue base and the overlying recipient flap and it also avoided a horizontal or vertical releasing incision. Additionally an excellent color match was seen post-operatively.

In a previous study, the use of subepithelial connective tissue graft has shown predictable results in reconstructing a lost gingival papilla. Interposed connective tissue graft relies on dual blood supply thus enhancing the survival of the graft and increasing the predictability of the surgical technique ${ }^{19}$. The surgical technique described in our case series uses a similar method wherein we have used PRF instead of subepithelial connective tissue graft. This avoids a second surgical site for graft procurement. This also increases patient's acceptance of the treatment.

Platelet rich fibrin, a second generation platelet concentrate is widely used to accelerate soft and hard tissue healing because of presence of many growth factors. PRF was first developed in France by Choukroun etal. ${ }^{20}$ PRF consists of an intimate assembly of cytokines and structural glycoproteins enmeshed within a slowly polymerized fibrin network.

The advantages of PRF are its simplified preparation and lack of biochemical handling of the blood and its autologous nature. Beneficial effects of PRF have been studied in various procedures, such as facial plastic surgery, ${ }^{21}$ gingival recessions, ${ }^{22}$ as a sole osteoconductive filling material in sinus lift procedures, ${ }^{20,23}$ intraosseous periodontal defects, ${ }^{24,25}$ and treatment of furcation defects. ${ }^{26}$

This surgical technique resulted in an enhancement of the height of the papilla, resulting in a change in the PPI score from 2 to PPI score 1 in all the cases treated. Though there was an earlier system in existence for the classification of loss of papillary height, this new PPI index was more helpful in the measurement of papillary height pre and post treatment levels and comparing the gain of papillary tissue post treatment. 
CONCLUSION: This novel surgical procedure combined the use of semilunar incision and platelet rich fibrin for augmenting the lost interdental papilla in the anterior esthetic zone. There was good patient acceptability for this minimally invasive technique as it is associated with reduced donor site morbidity. The procedure can be recommended in appropriate cases for papilla reconstruction as there was complete papillary fill achieved in all the treated cases.

\section{REFERENCES:}

1. Kokich VG. Esthetics: The Orthodontic-Periodontic Restorative Connection. Semin Orthod. 1996; 2:21-30.

2. Kokich JR, Kyak HA, Shapiro PA. Comparing the Perception of Dentists and Lay People to Altered Dental Aesthetics. J Esthet Dent. 1999; 11: 311-324.

3. Kurth J, Kokich V. Open Gingival Embrasures after Orthodontic Treatment in Adults: Prevalence and Etiology. Am J Orthod Dento Facial Orthop. 2001; 120: 116-123.

4. Shapiro A. Regeneration of Interdental Papillae Using Periodic Curettage. Int J Periodontics Restorative Dent. 1985; 5 (5):27-33.

5. Beagle JR. Surgical Reconstruction of the Interdental Papilla: Case Report. Int J Periodontics Restorative Dent. 1992; 12:145-151.

6. Han TJ, Takei HH. Progress in Gingival Papilla Reconstruction. Periodontol 2000. 1996; 1:65-68.

7. Azzi R, Carranza FA, Etienne D. Surgical Reconstruction of the Interdental Papilla. Int J Periodontics Restorative Dent. 1998; 18: 467-473.

8. Azzi R, Etienne D, Sauvan JL, Miller PD. Root Coverage and Papilla Reconstruction in Class IV Recession: A Case Report. Int J Periodontics Restorative Dent. 1999; 19: 449-455.

9. Azzi R, Takei HH, Etienne D, Carranza FA. Root Coverage and Papilla Reconstruction Using Autogenous Osseous and Connective Tissue Grafts. Int J Periodontics Restorative Dent. 2001; 21 (2):141-147.

10. Nemcovsky CE. Interproximal Papilla Augmentation Procedure: A Novel Surgical Approach and Clinical Evaluation of 10 Consecutive Procedures. Int J Periodontics Restorative Dent. 2001; 21 (6):553-559.

11. Carnio J. Surgical Reconstruction of Interdental Papilla Using an Interposed Subepithelial Connective Tissue Graft: A Case Report. Int J Periodontics Restorative Dent. 2004; 24(1):31-37.

12. Prato GP, Rotundo R., Cortellini P, Tinti C, Azzi R. Interdental Papilla Management: A Review and Classification of The Therapeutic Approaches. Int J Periodontics Restorative Dent. 2004; 24 (3):246-255.

13. Carranza N, Odont, Zogbi C. Reconstruction Of The Interdental Papilla With An Underlying Subepithelial Connective Tissue Graft: Technical Considerations and Case Reports. Int J Periodontics Restorative Dent. 2011; 31: 45-50.

14. Cardaropoli D, Re S, Corrente G, Abundo R. Reconstruction Of The Maxillary Midline Papilla Following A Combined Orthodontic-Periodontic Treatment In Adult Periodontal Patients. J Clin Periodontol. 2004; 31:79-84.

15. Chow YC, Eber RM, Tsao YP, Shotwell JL, Wang HL. Factors Associated With The Appearance Of Gingival Papillae. J Clin Periodontol. 2010; 37:719-727. 
16. Zetu L, Wang Z. Management of Interdental/ Inter- Implant Papilla. J Clin Periodontol. 2005; 32(7): 831-839.

17. Tarnow DP, Magner AW, Fletcher P. The Effect Of The Distance From The Contact Point To The Crest Of Bone On The Presence Or Absence Of The Interproximal Dental Papilla. J Periodontol. 1992; 63: 995-996.

18. Kleinheinz J, Büchter A, Kruse-Lösler B, Weingart D, Joos U. Incision Design In Implant Dentistry Based On Vascularisation Of The Mucosa. Clin Oral Implants Res. 2005; 16 (5): 518-523.

19. Langer B, Langer L. Subepithelial Connective Tissue Graft Technique For Root Coverage. J Periodontol. 1985; 5: 715-720.

20. Choukroun J, Dohan DM, Simonpieri A, Schoeffler C, Dohan SL, Dohan AJ, Et Al. Platelet Rich Fibrin (Prf): A Second Generation Platelet Concentrate: Part V: Histologic Effects Of Prf Effects On Bone Allograft Maturation In Sinus Lift. Oral Surg Oral Med Oral Patho Oral Radio Endod. 2006; 101: 299-303.

21. Charrier JB, Monteil JP, Albert S, Collon S, Bobin S, Dohan DM. Relevance Of Choukroun's Platelet Rich Fibrin (Prf) And Smas Flap In Primary Reconstruction After Superficial Or Subtotal Parotidectomy In Patients With Focal Pleiomorphic Adenoma: A New Technique. Rev Laryngol Otol Rhinol (Bord). 2008; 129: 313-318.

22. Anilkumar K, Geetha A, Umasudhakar, Ramakrishnan T, Vijayalakshmi R, Pameela E. Platelet Rich Fibrin: A Novel Root Coverage Approach. J Indian Soc Periodontol. 2009; 13(1):50-54.

23. Mazor Z, Horowitz RA, Corso MD, Prasad HS, Rohrer MD, Dohan DM. Sinus Floor Augmentation With Simultaneous Implant Placement Using Choukroun's Platelet-Rich Fibrin As The Sole Grafting Material: A Radiologic And Histologic Study At 6 Months. J Periodontol. 2009; 80(12):2056-2064.

24. Thorat MK, Pradeep AR, Pallavi B. Clinical Effects of Autologous Platelet Rich Fibrin in the Treatment of Intra Bony Defects: A Controlled Clinical Trial. J Clin Periodontol. 2011; 38: 925932.

25. Sharma A, Pradeep AR. Treatment Of 3-Wall Intrabony Defects In Chronic Periodontitis Subjects With Autologous Platelet Rich Fibrin - A Randomized Controlled Clinical Trial. J Periodontol. 2011; 82: 1705-1712.

26. Sharma A, Pradeep AR. Autologous Platelet-Rich Fibrin in the Treatment of Mandibular Degree Ii Furcation Defects: A Randomized Clinical Trial. J Periodontol. 2011; 82: 1396-1403.

\section{CASE 1:}

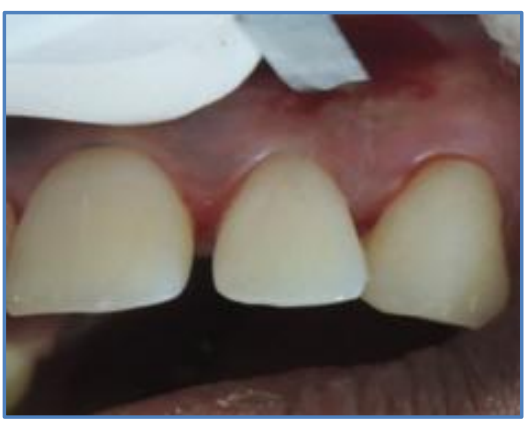

Fig. 1: Preoperative view showing loss of interdental papillae in 22,23 region

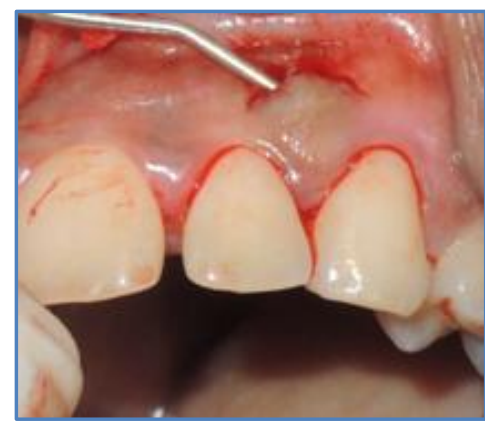

Fig. 2: Incision placed and pouch created 


\section{CASE REPORT}

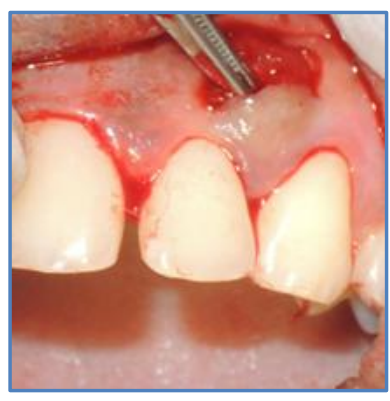

Fig. 3: PRF tucked in to the pouch created pushing the gingivopapillary complex coronally

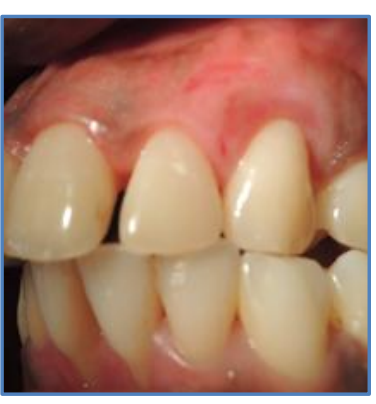

Fig. 4: 10 days post-operative healing

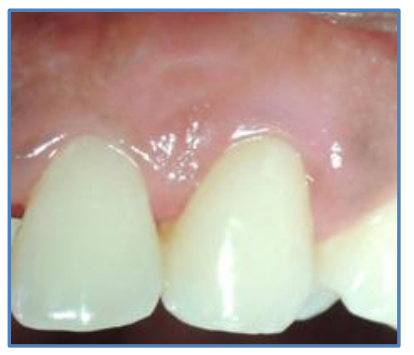

Fig. 5: 1 Month Postoperative View

\section{CASE 2:}

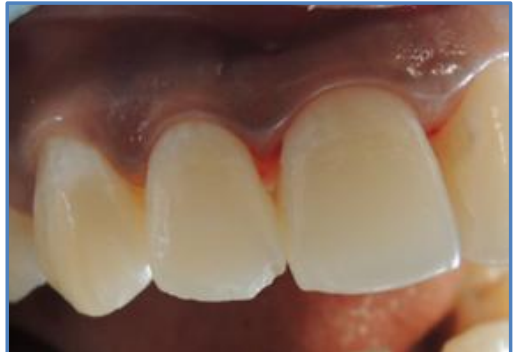

Fig. 6: Preoperative view showing black triangle in the region of 11,12

CASE 3:

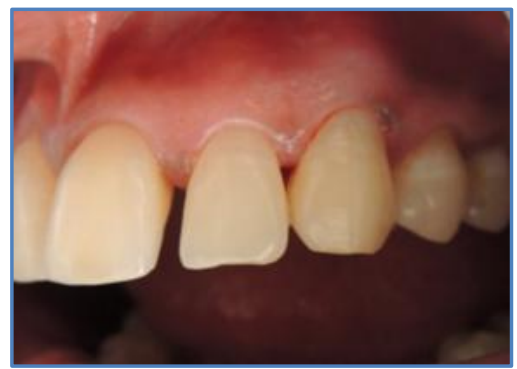

Fig. 7: Preoperative view showing black triangle in the region of 22,23

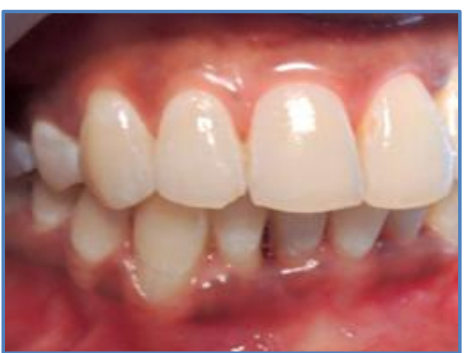

Fig. 6a: 1 month postoperative view

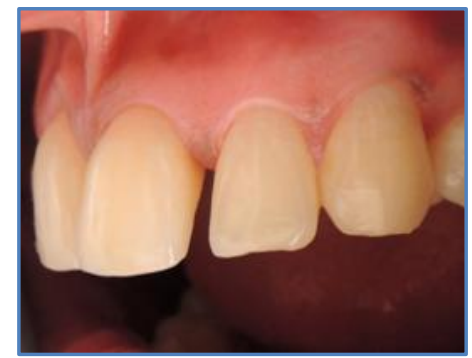

Fig. 7a: 1 month postoperative view 


\section{CASE REPORT}

\section{CASE 4:}

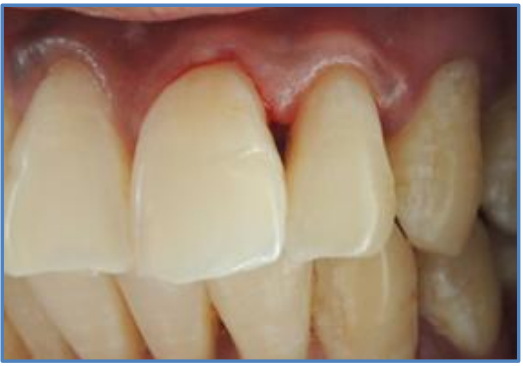

Fig. 8: Preoperative view showing black triangle in the region of 21,22

\section{AUTHORS:}

1. Nehal Sanghani

2. Ashwini Apine

3. Shivaprasad B. M.

4. Ritesh K.

5. Nalini M. S.

\section{PARTICULARS OF CONTRIBUTORS:}

1. Post Graduate Student, Department of Periodontology, Rajarajeswari Dental College and Hospital, Bangalore.

2. Post Graduate Student, Department of Periodontology, Rajarajeswari Dental College and Hospital, Bangalore.

3. Reader, Department of Periodontology, Rajarajeswari Dental College and Hospital, Bangalore.

4. Reader, Department of Periodontology, Rajarajeswari Dental College and Hospital, Bangalore.

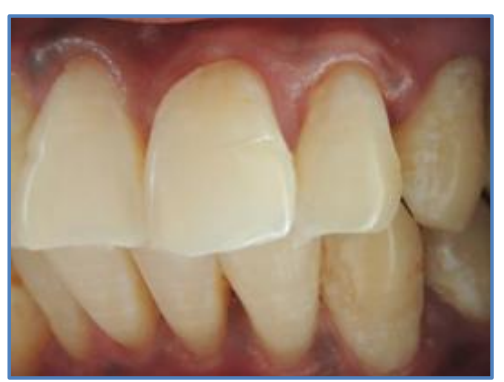

\section{Fig. 8a: 1 month postoperative view}

5. Reader, Department of Periodontology, Rajarajeswari Dental College and Hospital, Bangalore.

\section{NAME ADDRESS EMAIL ID OF THE CORRESPONDING AUTHOR:}

Dr. Nehal Sanghani, Department of Periodontology, Rajarajeswari Dental College and Hospital, Mysore Road,

Ramohalli Cross, Kumbalgodu,

Bangalore- 560074.

E-mail:nehalsanghani.09@gmail.com

Date of Submission: 06/04/2014.

Date of Peer Review: 07/04/2014.

Date of Acceptance: 11/04/2014.

Date of Publishing: 25/04/2014. 